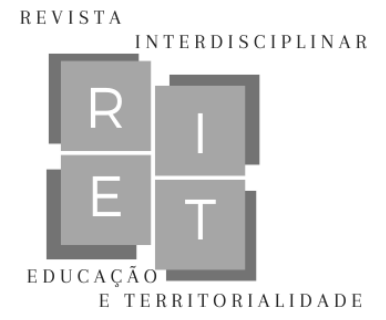

\title{
Entrevista: \\ O que a geografia da saúde por Raul Borges Guimarães tem a dizer sobre a Covid-19
}

\author{
What the geography of health by Raul Borges Guimarães has to say about \\ Covid-19
}

Lo que la geografía de la salud por Raul Borges Guimarães tiene que decir sobre el covid-19

Adeir Archanjo da Mota

Programa de Pós-Graduação em Geografia, Universidade Federal da Grande Dourados (UFGD)

Dourados, Mato Grosso do Sul, Brasil

E-mail: adeirmota@ufgd.edu.br

ORCID: https://orcid.org/0000-0002-8511-1572

Alexandre Bergamin Vieira

Programa de Pós-Graduação em Geografia, Universidade Federal da Grande Dourados (UFGD)

Dourados, Mato Grosso do Sul, Brasil

E-mail: alexandrevieira@ufgd.edu.br

ORCID: https://orcid.org/0000-0003-3055-3143

Andréia Sangalli

Programa de Pós-Graduação em Educação e Territorialidade, Universidade Federal da Grande

Dourados (UFGD)

Dourados, Mato Grosso do Sul, Brasil

E-mail: andreiasangalli@ufgd.edu.br

ORCID: https://orcid.org/0000-0002-2297-4282

Cássio Knapp

Programa de Pós-Graduação em Educação e Territorialidade, Universidade Federal da Grande

Dourados (UFGD)

Dourados, Mato Grosso do Sul, Brasil

E-mail: cassioknapp@ufgd.edu.br

ORCID: https://orcid.org/0000-0003-2237-9966

DOI: $10.30612 /$ riet.v\%vi\%i.15014

Desde os anos 2000, a comunidade geográfica brasileira se interessou cada vez mais pelo debate da saúde coletiva, sendo um marco desse processo a realização do I Simpósio Nacional de Geografia da Saúde, em dezembro de 2003, na cidade de Presidente Prudente (SP). Desde então, a cada dois anos têm ocorrido outros simpósios, reunindo os

RIET- ISSN 2676-0355, Dourados, v. 2, n. 2, p. 440 a 447, jan./jun., 2021 


\section{Entrevista:}

\section{O que a geografia da saúde por Paul Borges Guimarães tem a dizer sobre a Covid-19}

pesquisadores da geografia no desafio de compreender novos significados da saúde e da vida na cidade ou no campo. Assim, a interface geografia e saúde fazem parte de um sistema de ideias em evolução e de um movimento mais amplo de consolidação do campo da saúde coletiva (GUIMARÃES, 2016, p.871).

A grande contribuição da Geografia para a compreensão da sociedade seria o estudo do espaço social, assim como o da História seria o estudo do tempo social. Por sua vez, o campo da ciência geográfica deveria ter como ponto de partida e de chegada a melhor compreensão das dimensões espaciais da vida social, aprofundando-se os conceitos geográficos de território, região e lugar (GUIMARÃES, 2015, p.47).

O ponto de partida é a inserção de nosso corpo no mundo. Sim, o corpo humano não é apenas um corpo anatomofisiológico, mas também um corpo social. As diferenças corporais servem como base para formas socioespaciais de inclusão e empoderamento, exclusão e opressão, produzindo experiências diferenciadas de saúde e doença. E o desafio é compreender os novos significados da vida social, do sentimento de pertencer a um território e dos processos geradores do interesse coletivo e comunitário daqueles que vivem e morrem em cada lugar (GUIMARÃES, 2015, p.50;51).

As características do meio impõem uma série de condições que conformam essa Geografia da saúde. Isso pode ser observado no período que vivemos. A exemplo, o mundo contemporâneo é marcado pela aceleração dos fluxos e pelo elevado conteúdo de ciência e tecnologia nos processos produtivos, impondo uma ordem e racionalidade na escala global. Mas essa racionalidade atinge desigualmente os territórios nacionais, regiões e lugares (GUIMARÃES, 2015, p.52).

Em 2020, um novo desafio de investigação foi imposto a geografia da saúde: a COVID-19. A disseminação acelerada do Coronavírus no Brasil, resultou em necessidade de mudanças inesperadas e readequações em todos os setores da sociedade brasileira, e ocasionou maiores preocupações em relação ao setor ou rede de saúde pública brasileira, em específico ao Sistema único de Saúde - SUS, visto que ao longo da história tem resistido, mesmo sem a devida atenção por parte dos governantes, principalmente pela falta de infraestrutura para o funcionamento e atendimento à população.

A rede de saúde pode ser compreendida como um sistema interconectado que funciona por meio da circulação de pessoas, mercadorias ou informações. Neste sentido, a rede de saúde não é um dado, mas uma questão em aberto. Não se trata só de uma rede de

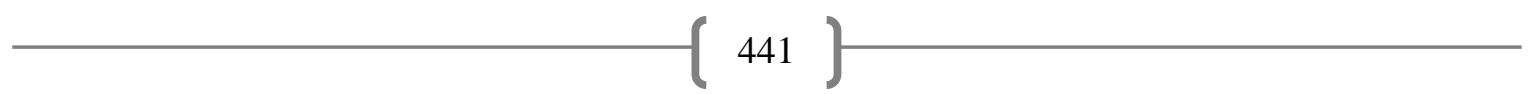

RIET-ISSN 2676-0355, Dourados, v. 2, n. 2, p. 440 a 447, jan./jun., 2021 


\section{Entrevista:}

\section{O que a geografia da saúde por Paul Borges Guimarães tem a dizer sobre a Covid-19}

equipamentos conectados, mas de um conjunto de atores sociais que a frequentam em busca de um objetivo ou para cumprir uma tarefa bem localizada territorialmente. Cada um destes atores (corpo técnico dos hospitais e unidades básicas de saúde, usuários dos serviços, lideranças das associações de moradores, entre outros) ocupa uma posição relativa, ou seja, um nó conectado na rede de saúde (GUIMARÃES, 2001, p.157).

Tomando como referência essa compreensão dos eventos em saúde em suas conexões com a totalidade, ressaltamos que a difusão espacial da Covid-19 não se trata de um problema de saúde pública nos mesmos moldes que outras pandemias trouxeram, mas de um desafio a ser enfrentado cada vez mais relevante no mundo globalizado em que vivemos. Assim, alteraram-se as escalas da vida e da economia, ampliaram-se os cruzamentos impostos por um mundo mais complexo, e por isso se torna necessário transformar nosso olhar para novos problemas (Guimarães, et al., 2020, p.120).

A disseminação do Coronavírus é mais um exemplo marcado por uma aceleração gradativa da intervenção humana nos processos naturais. A descoberta do fogo e a domesticação de plantas e animais foram algumas das primeiras técnicas que alteraram significativamente a relação da sociedade com a natureza. Em seu nicho ecológico, muitos parasitos não causavam doenças nem nos animais ou nos homens. Em contato com os agrupamentos humanos, esses parasitos encontraram novos hospedeiros com condições muito mais favoráveis, infectando rapidamente os organismos (focos naturais). (GUIMARÃES, 2015, p.60).

O mapeamento e análise da COVID-19 no território permite constatar que sua evolução se dá estreitamente associada a essas estruturas territoriais, que são formas fixas associadas aos fluxos por elas conformadas... Em razão dessas características, a geografia pode fornecer subsídios não somente ao diagnóstico das dinâmicas territoriais dos casos da doença, mas também para a realização de prognósticos que possam orientar as ações de saúde pública, desde que respeitadas e compreendidas as especificidades desse fenômeno em cada lugar (Guimarães, et al., 2020, p.134;136).

Diante da breve exposição, destaca-se a importância da geografia da saúde em busca de respostas aos cenários que se desenharam a partir da COVID-19, e para ampliar essas discussões, o professor e pesquisador Raul Borges Guimarães, pautará algumas considerações sobre esse contexto.

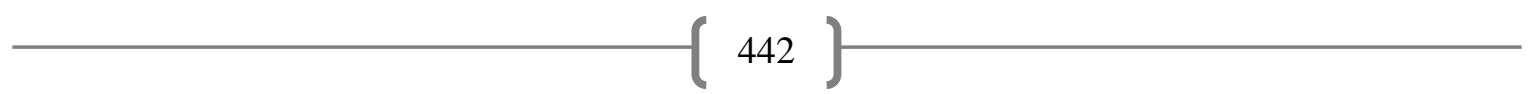

RIET-ISSN 2676-0355, Dourados, v. 2, n. 2, p. 440 a 447, jan./jun., 2021 
O que a geografia da saúde por Paul Borges Guimarães tem a dizer sobre a Covid-19

Ao considerar a Geografia da Saúde, como uma das abordagens temáticas da Geografia, e como um campo de conhecimento que tem crescido e se consolidado nas últimas décadas no Brasil, como o professor percebe as contribuições desta abordagem frente a pandemia da COVID-19 no país?

Raul Borges Guimarães: De fato, nos últimos 30 anos, com apoio financeiro da CAPES e $\mathrm{CNPq}$ (diga-se de passagem), foram realizadas reuniões bianuais entre os geógrafos brasileiros preocupados com a temática da saúde. Ao mesmo tempo, ocorreu uma expansão dos estudos no nível de mestrado e doutorado. O resultado desse processo foi a formação de uma expressiva comunidade de geógrafos brasileiros especialistas na temática da saúde. Este coletivo, logo no início da pandemia da Covid-19 organizou uma força tarefa para trocar experiências e atender às demandas dos gestores de saúde de municípios e estados das diferentes regiões do país. Temos bons resultados alcançados em praticamente todas as unidades da federação.

O Brasil, um país de proporções continentais, tem no SUS, o maior nível de abrangência dos serviços de saúde pública do mundo, mas tem apresentado muitas dificuldades para controlar a Pandemia. De que forma, o poder público poderia contribuir para que, os trabalhos de investigações realizados por grupos de pesquisa, como os que o senhor colabora, pudessem refletir em ações mais eficazes no combate a Pandemia?

Raul Borges Guimarães: A força tarefa de geógrafos da saúde desenvolveu análise acerca da distribuição dos casos de COVID, assim como identificou tendências. Também foram realizados estudos de vulnerabilidade social. Esses estudos poderiam se somar a outros esforços de planejamento territorial, mas para isso seria preciso aumentar a testagem em massa na população para que o Brasil pudesse compreender melhor as rotas de dispersão viral no território nacional.

Os primeiros casos de COVID-19 no Brasil, foram registrados em grandes centros, lugares com bastante trânsito internacional, como: São Paulo, Rio de Janeiro, Manaus e Fortaleza. Já é possível compreender como o Sars-CoV-2 se interiorizou no país?

Raul Borges Guimarães: Sim, o processo de interiorização se completou em novembro/dezembro do ano passado. Ocorreu um caso clássico de difusão espacial hierárquica, como já descrito em epidemias de doenças virais. Neste caso, a disseminação 


\section{O que a geografia da saúde por Paul Borges Guimarães tem a dizer sobre a Covid-19}

ocorreu das cidades maiores para as menores, passando pelos centros regionais, que se transformaram em centros dispersores do vírus para o interior do país. Certamente, os eixos rodoviários que interligam os principais centros urbanos do país foram rotas de dispersão da doença, como observamos no mapa abaixo, para o Estado de São Paulo ainda em abril de 2020.

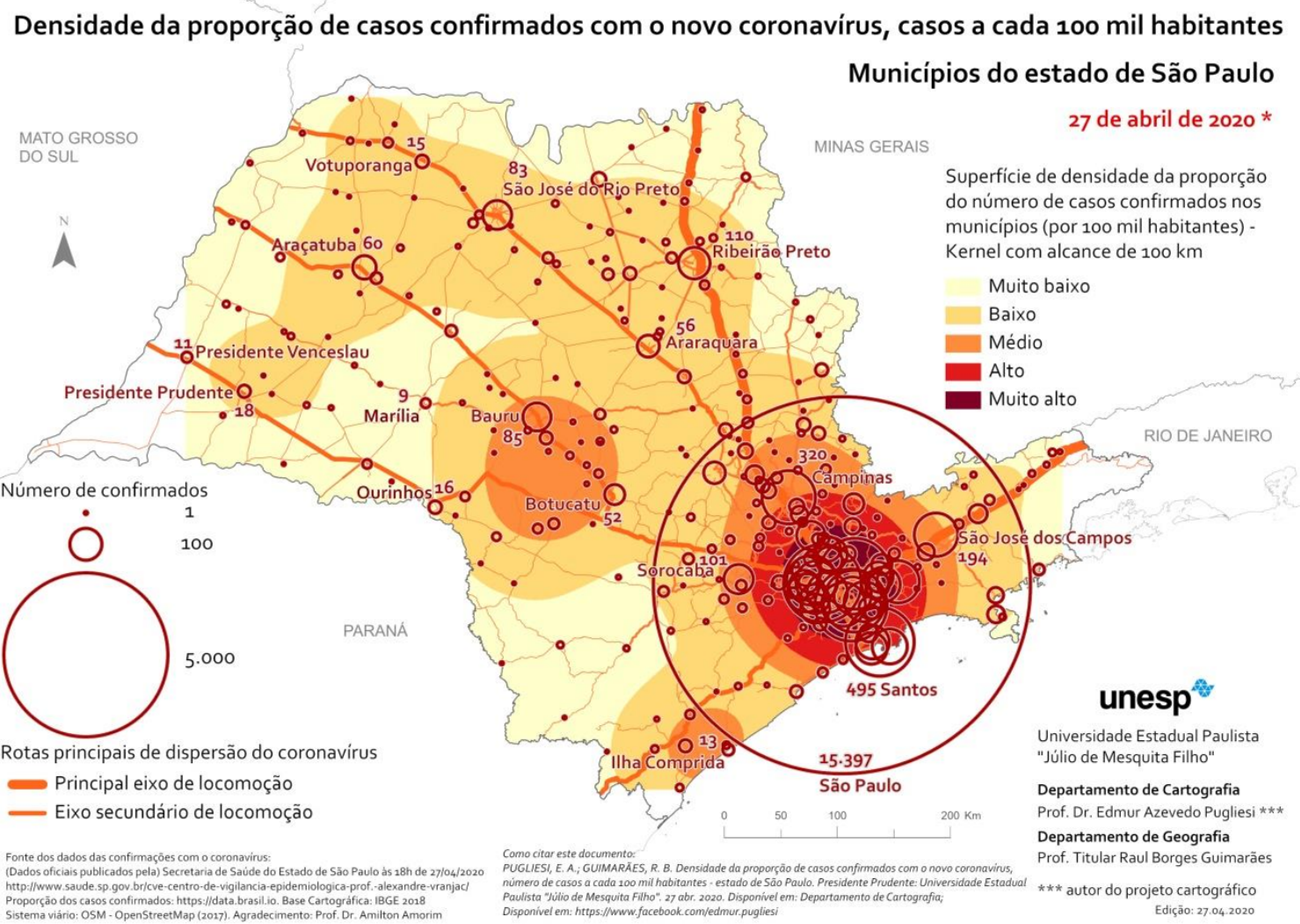

Fonte: https://covid19.fct.unesp.br/mapeamento-cartografico/\#densidade-casos

Desde dezembro de 2019, circulava nos mais diversos meios de comunicação rumores de um vírus com potencial poder de contágio e letalidade. Após 1 ano do registro da primeira morte no Brasil em decorrência da COVID-19, com o registro de tantos infectados e um número tão alto do mortes. Em sua análise, quais fatores contribuíram para que o Brasil, principalmente a partir da chamada "segunda onda", se transformasse em um foco mundial de preocupação com a Pandemia?

Raul Borges Guimarães: Sem dúvidas, a falta de uma articulação nacional sob o comando do Ministério da Saúde foi o principal fator responsável para o Brasil se transformar em um dos principais epicentros mundiais da pandemia a partir da $2 \mathrm{a}$ onda. Dadas as dimensões continentais do país e as enormes disparidades regionais, criou-se uma situação complexa com diversos ciclos virais em ritmos e escalas diferentes. Somente uma

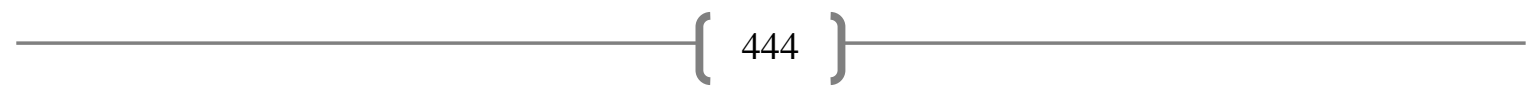

RIET-ISSN 2676-0355, Dourados, v. 2, n. 2, p. 440 a 447, jan./jun., 2021 
O que a geografia da saúde por Paul Borges Guimarães tem a dizer sobre a Covid-19

análise de conjunto com base nas ferramentas científicas da epidemiologia e também da geografia, podemos encontrar uma saída para a pior crise sanitária da história do Brasil.

As novas mutações do vírus resultaram em aceleração das taxas de contágio e de letalidade. Estas novas variantes mudaram o padrão espacial de disseminação no Brasil em relação ao que aconteceu no primeiro semestre de 2020?

Raul Borges Guimarães: Como a circulação viral encontra-se por toda parte, o número de casos passou a ocorrer ao mesmo tempo em diferentes tipos de cidade. A resposta ao problema tornou-se mais complexa.

Ao considerar o processo histórico que resultou em uma sociedade que apresenta altos índices de desigualdades sociais, econômicas, educacionais, que impões grandes desafios para grupos sociais mais periféricos, seja na cidade, seja no campo, seja indígena, quilombola, camponesa, ribeirinha, ou seja, toda a classe de trabalhadoras e trabalhadores brasileiros. E visto que essas desigualdades se ampliaram significativamente com a Pandemia da COVID-19. Em sua análise, era previsível que a população mais vulnerável do país fosse a mais atingida pela Pandemia, quais políticas governamentais poderiam ser implementadas para atenuar essa crise? E o que caberia à sociedade civil e às organizações sociais?

Raul Borges Guimarães: Sim, era esperado que a letalidade seria maior nos grupos mais vulneráveis. $\mathrm{O}$ apoio financeiro aos mais pobres foi uma medida importante, ainda que tenha demorado muito para ser implementado. Faltou uma ajuda mais efetiva para os pequenos empresários segurarem os empregos, mesmo que mantendo os funcionários em isolamento social. Temos relatos de experiências exitosas de controle social da pandemia, o que ocorreu muito mais pela capacidade de organização do movimento social do que medidas de maior capilaridade das ações do Estado para a proteção da vida. Quanto à sociedade civil, temos vários exemplos de mobilização social exitosas para o enfrentamento da COVID-19. Diversas comunidades indígenas criaram barreiras sanitárias para controlar a entrada e a saída de pessoas de suas terras, o que mesmo se verificou em diversas comunidades de favelas.

Considerando as mudanças na disseminação do novo coronavírus, da taxa de mortalidade entre pessoas socioeconomicamente mais vulneráveis, da queda da média de idade de pacientes internatos, entre outras alterações identificadas desde o início da Pandemia até agora. É possível afirmar que o Plano Nacional de Imunização, que já

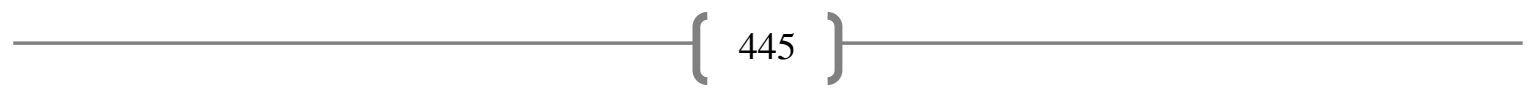

RIET-ISSN 2676-0355, Dourados, v. 2, n. 2, p. 440 a 447, jan./jun., 2021 
O que a geografia da saúde por Paul Borges Guimarães tem a dizer sobre a Covid-19

está na $5^{a}$ edição, foi elaborado de forma correta para promover o controle da pandemia no país?

Raul Borges Guimarães: O Plano Nacional de Imunização prioriza os grupos mais vulneráveis: a população mais velha, pessoas com co-morbidades, povos indígenas e quilombolas, sucessivamente. Em linhas gerais, a abordagem adotada é adequada.

A campanha de vacinação da COVID-19 no Brasil tem ocorrido de forma muito lenta, com diversos replanejamentos na entrega e produção das vacinas. Em abril de 2021, a OMS declarou que o Brasil não irá controlar a pandemia da Covid-19 apenas com vacinação. $O$ senhor vislumbra alguma tendência para o cenário brasileiro no segundo semestre de 2021 e início de 2022?

Raul Borges Guimarães: Teremos alguma ideia dessa questão somente no início de 2022. Como a vacinação é muito lenta, ainda não conseguimos freiar a circulação viral, o que favorece o desenvolvimento de outras variantes. Há um risco de surgir alguma variante que as vacinas não protejam. Tal situação colocaria o Brasil no pior cenário possível para 2022. Temos de continuar acompanhando os acontecimentos e utilizando das ferramentas da geografia para compreender o que está ocorrendo.

Considerando os impactos nos ecossistemas do planeta, acentuados pelo aumento das dinâmicas produtivas, do acirramento das desigualdades socioambientais, da mudança climática, dos grandes desastres ambientais, considerando também os aprendizados acumulados no manejo da pandemia da CoVID-19 e das anteriores, quais as principais mudanças necessárias para evitar novas pandemias de doenças infectocontagiosas?

Raul Borges Guimarães: Estamos diante da primeira pandemia do mundo globalizado. Certamente, não será a última. Já estão ocorrendo uma série de reuniões multilaterais entre as principais nações do mundo para construir uma agenda de vigilância da saúde global. Infelizmente, o Brasil não tem participado dessas discussões. A política externa adotadas pelo atual governo retirou do país o protagonismo que sempre teve, inclusive na discussão da saúde pública e das ações da Organização Mundial da Saúde.

Dados sobre o Entrevistado:

Raul Borges Guimarães, possui graduação em Geografia - Licenciatura e Bacharelado pela Pontifícia Universidade Católica de São Paulo (1985), mestrado em

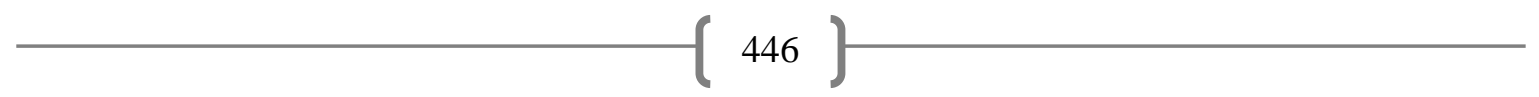

RIET- ISSN 2676-0355, Dourados, v. 2, n. 2, p. 440 a 447, jan./jun., 2021 


\section{O que a geografia da saúde por Paul Borges Guimarães tem a dizer sobre a Covid-19}

Geografia Humana pela Faculdade de Filosofia Letras e Ciências Humanas da USP (1994), doutorado em Geografia (Geografia Humana) pela mesma faculdade em 2000 e livre docência pela Faculdade de Saúde Pública da USP em 2008. Desenvolveu dois programas de pós-doutorado: em 2001, no Laboratório de Planejamento Urbano e Cidades Saudáveis da Universidade do Oeste da Inglaterra (UWE), em Bristol (Reino Unido); em 2009, no Departamento de Saúde Ambiental da Faculdade de Saúde Pública da Universidade de São Paulo. Atualmente é professor titular do Departamento de Geografia da Universidade Estadual Paulista Júlio de Mesquita Filho, campus de Presidente Prudente. Coordena o Laboratório de Biogeografia e Geografia da Saúde (Centro de Estudos do Trabalho, Ambiente e Saúde - CETAS). Tem experiência na área de Geografia, com ênfase em Geografia da Saúde, atuando também nos seguintes temas: geografia regional e urbana, política pública e cartografia temática. É bolsista produtividade do CNPQ, nível 1D e editor adjunto da Revista Saúde e Sociedade.

\section{Referências}

GUIMARÃES, R. B. Saúde urbana: velho tema, novas questões. Terra Livre, [S. l.], v. 2, n. 17, p. 155-170, 2015. Disponível em: https://publicacoes.agb.org.br/index.php/terralivre/article/view/344. Acesso em: 24 jul. 2021.

GUIMARÃES, Raul Borges. Geografia e saúde coletiva no Brasil. Saúde Soc. São Paulo, v.25, n.4, p.869-879, 2016. Disponível em: https://www.scielo.br/j/sausoc/a/ByYQCmppfzfSnT8pWpQr7HR/?lang=pt. Acesso em: 24 jul. 2021.

GUIMARÃES, R. B., Catão, R. de C., MARTINUCI, O. da S., PLUGIESI, E. A., \& MATSUMOTO, P. S. S. (2020). O raciocínio geográfico e as chaves de leitura da Covid-19 no território brasileiro. Estudos Avançados, v.34, n.99, p.119-139. Disponível em: https://www.revistas.usp.br/eav/article/view/173374. Acesso em: 24 jul. 2021.

GUIMARÃES, RB. Saúde: fundamentos de Geografia humana [online]. São Paulo: Editora UNESP, 2015, 109 p. ISBN 978-85-68334-938-6. Available from SciELO Books. Disponível em: https://static.scielo.org/scielobooks/4xpyq/pdf/guimaraes-9788568334386.pdf. Acesso em: 24 jul. 2021.

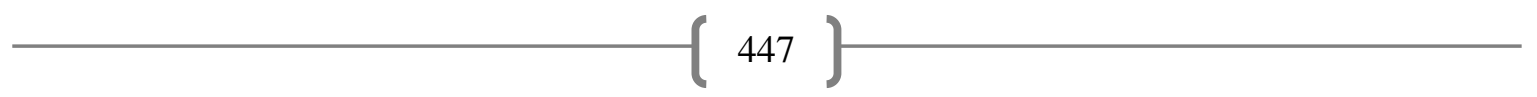

RIET-ISSN 2676-0355, Dourados, v. 2, n. 2, p. 440 a 447, jan./jun., 2021 